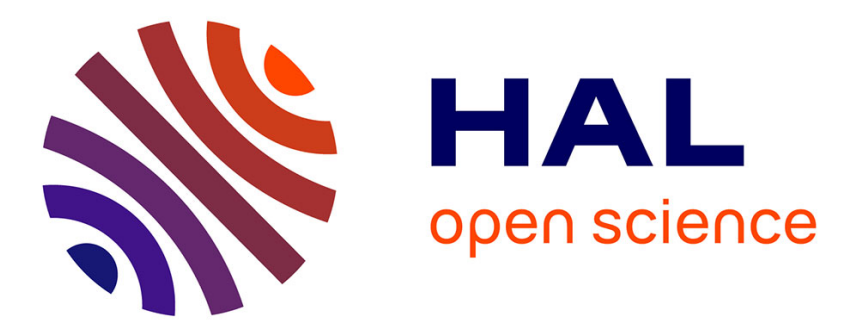

\title{
Extending Janzen's hypothesis to temperate regions: A test using subterranean ecosystems
}

Stefano Mammola, Elena Piano, Florian Malard, Philippe Vernon, Marco Isaia

\section{To cite this version:}

Stefano Mammola, Elena Piano, Florian Malard, Philippe Vernon, Marco Isaia. Extending Janzen's hypothesis to temperate regions: A test using subterranean ecosystems. Functional Ecology, 2019, 33 (9), pp.1638-1650. 10.1111/1365-2435.13382 . hal-02181396

\section{HAL Id: hal-02181396 https://hal-univ-rennes1.archives-ouvertes.fr/hal-02181396}

Submitted on 17 Sep 2019

HAL is a multi-disciplinary open access archive for the deposit and dissemination of scientific research documents, whether they are published or not. The documents may come from teaching and research institutions in France or abroad, or from public or private research centers.
L'archive ouverte pluridisciplinaire HAL, est destinée au dépôt et à la diffusion de documents scientifiques de niveau recherche, publiés ou non, émanant des établissements d'enseignement et de recherche français ou étrangers, des laboratoires publics ou privés. 


\section{Functional Ecology}

DR STEFANO MAMMOLA (Orcid ID : 0000-0002-4471-9055)

FLORIAN MALARD (Orcid ID : 0000-0001-8037-4464)

Article type : Research Article

Section: Animal Physiological Ecology

Editor: Dr Enrico Rezende

\section{Extending Janzen's hypothesis to temperate regions: a test using subterranean ecosystems}

Stefano Mammola ${ }^{1,2,}$, Elena Piano ${ }^{1}$, Florian Malard $^{3}$, Philippe Vernon ${ }^{4}$, Marco Isaia $^{1,{ }^{* *}}$

1. Department of Life Sciences and Systems Biology, University of Turin, Turin, Italy.

2. LIBRe - Laboratory for Integrative Biodiversity Research, Finnish Museum of Natural History, University of Helsinki, Helsinki, Finland

3. Univ Lyon, Université Claude Bernard Lyon 1, CNRS UMR 5023, ENTPE, Laboratoire d'Ecologie des Hydrosystèmes Naturels et Anthropisés, Villeurbanne, France

4. Univ Rennes, Université Rennes 1, CNRS UMR 6553, ECOBIO, Station Biologique de Paimpont, France

* corresponding author: stefano.mammola@ unito.it, tel. 0116704544; OrcidID:0000-0002-4471-9055

** corresponding author: marco.isaia @ unito.it, tel. 0116704544; OrcidID:0000-0001-5434-2127 
Running title: Extending Janzen's hypothesis to caves

Keywords: Climate Variability Hypothesis, Janzen's hypothesis, Range size, Thermal tolerance, Climate change, Rapoport's rule, Subterranean biology, Western Italian Alps

\section{ABSTRACT}

1. Janzen's hypothesis (1967; American Naturalist) predicts that tropical habitats with reduced thermal seasonality would select for species with narrow thermal tolerance, thereby limiting dispersal among sites of different elevations showing little overlap in temperature. These predictions have so far been tested by confronting tropical and temperate mountain communities, leaving unresolved the question of their generalization to habitats with low thermal seasonality outside the tropics.

2. We provide the first extension of Janzen's hypothesis to temperate habitats, by testing for differences in thermal tolerance and elevational range among congeneric alpine spiders (Araneae: Linyphiidae: Troglohyphantes) occurring along a steep gradient of decreasing thermal seasonality with increasing cave depth. Using species from the same temperate region rather than from distinct biogeographic regions, avoids confounding the effects of short- and long-term climatic variability on thermal tolerance and elevational range extent.

3. Following Jansen's assumptions, we predicted that cave habitats with low thermal seasonality would select for narrow thermal tolerance. Also, specialized subterranean species would exhibit both narrower elevational range extents and smaller realized thermal niche breadths. Initially, we showed that thermal seasonality and the overlap in temperature across caves were considerably lower in deep than in shallow cave habitats. Then, we measured thermal tolerance and used morphological traits to quantify the degree of specialization to subterranean life of eleven spider species.

4. We found that thermal tolerance decreased with increasing subterranean specialization. Deep subterranean species reached their critical temperature at 1 to $4{ }^{\circ} \mathrm{C}$ above their habitat temperature, whereas shallow subterranean species withstood a two-fold larger temperature increase. At last, we demonstrated that a species' elevational range extent and the variation 
of temperature encountered across its range decreased with increasing specialization to deep subterranean life.

5. Our integrative work, being grounded in organismal and habitat measures, represents the first generalization of Janzen's framework to caves and provides a conceptual framework to disentangle the effect of long-term climate variability on subterranean biodiversity patterns. Extending Janzen's thoughts to a broader range of ecosystems is key to understanding how the ecological specialization-dispersal tradeoff may constrain the response of species to climate change.

\section{INTRODUCTION}

Understanding the role of climate in determining species geographical distribution is a pivotal research topic in biogeography, macroecology and climate change biology (Deutsch et al., 2008; Mittelbach et al., 2007; Muñoz \& Bodensteiner, 2019; Shah et al., 2017; Sunday, Bates, \& Dulvy, 2011). Janzen's mountain passes hypothesis (Janzen, 1967) is a core contribution to understand how climatic variability influences a species thermal tolerance and, through this, its dispersal and elevational range. This hypothesis was originally developed to explain biodiversity patterns in tropical mountains. Janzen began by assuming that the degree to which a topographic barrier limited dispersal depends on the temperature gradient across that barrier. Then, he assumed that a greater seasonal stability of temperature, like in tropical mountains, would select for species with narrow thermal tolerance over time. By linking together these two assumptions, he predicted that tropical species would have greater difficulty than temperate species to disperse across mountain passes, because they would be more likely to encounter unsuitable climates. Consequently, Janzen concluded that mountain passes were figuratively "higher" in the tropics.

Janzen's hypothesis is compelling because it brings together the habitat features, the physiology, and the dispersal capacity of species, thereby providing a conceptual foundation for achieving a mechanistic understanding of diversity patterns across space and time . 
(Ghalambor, Huey, Martin, Tewksbury, \& Wang, 2006; Sheldon, Huey, Kaspari, \& Sanders, 2018). Yet, the challenge of comparing thermal tolerance, range size and dispersal ability of geographically-distant animal communities occurring in tropical and temperate mountain systems emphasizes the difficulty of rigorously testing this framework. Indeed, a comprehensive test of Janzen's hypothesis-i.e. a research tackling simultaneously all of its empirical assumptions - was proposed only after five decades from its original formulation (Polato et al., 2018; Smith, 2018). By studying invertebrate assemblages in tropical versus temperate mountain rivers, Polato et al. (2018) recently demonstrated that the mountain passes hypothesis might hold true for riverine communities. Building upon this milestone result, it should be theoretically possible to generalize Janzen's hypothesis more broadly, by testing whether it can be used to explain biodiversity patterns in non-tropical ecosystems with reduced climatic seasonality.

Caves represent unique experimental arenas for testing the assumptions of Janzen's hypothesis. Deep terrestrial subterranean habitats-deep caves and the maze of fissures and voids inaccessible to humans-are among the terrestrial habitats with the greatest climatic stability (Badino, 2010). In temperate caves, there are steep gradients in thermal seasonality from the outer (annual temperature variations comparable to the outside; Pipan, López, Oromí, Polak, \& Culver, 2011) to the inner sectors (annual variations in the order of few tenths of degrees; Badino, 2010; Cigna, 2002). This provides a unique opportunity to test for relations among habitat specialization, thermal tolerance and dispersal capacity in animal communities at a very local, rather than a continental, scale. Indeed, comparing geographically-distant communities such as temperate and tropical communities bears the risk of confounding the influence of short- and long-term climate variability on specialization and dispersal (Jansson \& Dynesius 2002; Stevens 1989). This confounding factor has long been debated when it comes to explaining the mechanisms causing an increase in species range size at higher latitudes (Morueta-Holme et al., 2013; Rohde, 1996; Veter et al., 2013), i.e. the Rapoport's rule as described by Stevens (1989). 
Here, we provide the first explicit test of Janzen's hypothesis in subterranean habitats, by measuring the thermal tolerance of the widest sample of congeneric subterranean organisms to date, and relating thermal tolerance to the degree of subterranean specialization and to the extent of the elevation range. We used spiders of the genus Troglohyphantes (Araneae: Linyphiidae) as experimental model organisms (Fig. 1). Troglohyphantes spiders show different levels of subterranean habitat specialization, thus representing multiple replicates of the ecological transition along a gradient from shallow and thermally variable to deep and thermally stable subterranean habitats (Isaia et al., 2017; Mammola et al., 2018a). We tested eleven congeneric species distributed in the restricted biogeographic area of the Western Alps (Isaia et al., 2017; Mammola, Goodacre, \& Isaia, 2018), hence evaluating differences in thermal tolerance and dispersal among species sharing a common biogeographic history but occurring in habitats of contrasted thermal seasonality.

We initially explored the upper thermal tolerance of these species via thermal test experiments in a climatic chamber. Subsequently, we estimated the subterranean specialization of each species using a quantitative approach based on morphological traits (Mammola et al., 2018a), and related this specialization to their thermal tolerance. We predicted that increasing levels of subterranean specialization would result in narrower ranges of thermal tolerance, because the more specialized subterranean species colonize the deeper, seasonally stable cave habitats. Then, we related thermal tolerance to the elevational range extent as well as to the variation in temperature across that range (hereafter 'realized thermal niche breadth'). We predicted that more specialized subterranean species would exhibit both narrower elevational ranges and smaller realized thermal niche breadths. Corroborating the two predictions would provide an extension of Janzen's hypothesis to habitats with reduced thermal seasonality other than to tropical mountains (Polato et al., 2018), by linking a subterranean species' morphological and thermal specialization to its dispersal potential across elevation gradients. 


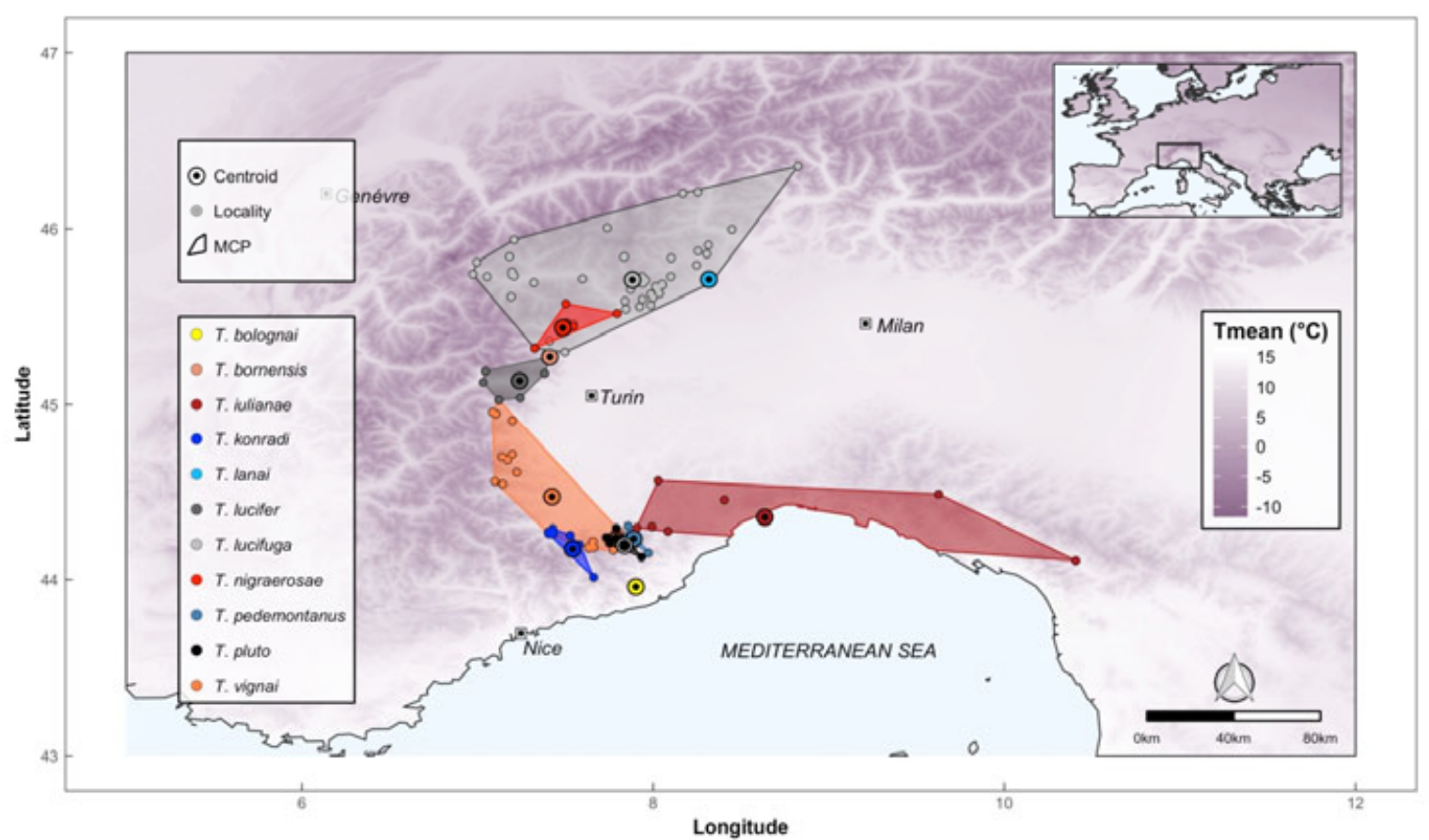

Figure 1. Distribution of Troglohyphantes spiders in the Western Italian Alps. For each species, localities and centroid of the distribution are reported. For visual presentation, the Minimum Convex Polygon (MCP) encompassing all localities of each species is drawn. Shades of gray in the background represent mean annual temperature, as derived from Bioclim 2 (Fick \& Hijmans, 2017). 


\section{MATERIALS \& METHODS}

\section{Thermal overlap for deep and shallow cave habitats}

To test whether thermal gradients are less overlapping for spiders inhabiting deep cave sectors, we used best available thermal records in the Western Italian Alps to compare the overlap in temperature at shallow and deep cave sectors. We used thermal data collected between 2012 and 2014. Temperature measurements were taken every $3 \mathrm{~h}$ through the whole sampling period, using Hygrochron ${ }^{\mathrm{TM}}$ dataloggers (accuracy: $\pm 0.5^{\circ} \mathrm{C}$ ) placed both at the cave entrance (1-10 m from the surface) and deeper inside the cave (>100 m or at the deepest point when caves were less than $100 \mathrm{~m}$ in length). Data were taken in multiple caves across our study region, covering an elevational range from 400 to over 2,000 m a.s.l. (full details in Mammola et al., 2018b). Following Scheffers et al. (2017), we plotted the range of thermal regimes and determined daily overlap values between the superficial and deep subterranean temperature regimes across caves opening at different elevations. We showed thermal overlap during only 2.5 months, because this was a timeframe for which all dataloggers were properly and simultaneously working in all caves (see details in Mammola et al., 2018b). The reported temperature patterns remain roughly the same for the whole period in which temperatures were recorded.

\section{Sampling protocol}

We collected live specimens of eleven species of Troglohyphantes from subterranean sites (caves, mines, subterranean military bunkers; hereinafter 'caves') across the Western Italian Alps (Table 1). With the exception of a very rare species inhabiting interstitial subterranean habitats of difficult access ( $T$. giachinoi Isaia \& Mammola), we sampled all known Troglohyphantes species occurring in this region. Samplings were conducted from early fall to late winter, which in our experience (Isaia \& Mammola, personal observations) corresponds to the period where Troglohyphantes spiders are generally mostly available in . 
caves. Due to the reduced detectability and generally low density of individuals, for a few species it was necessary to sample multiple caves to obtain a sufficient number of specimens (from 11 to 36 ) for the analysis (Table 1). In each cave, we collected spiders by hand and placed them in individual Eppendorf Tubes $®$ of $5 \mathrm{ml}$. We stored all vials in a coolbag and transported it the same day to the laboratory at the University of Turin (Italy), where we conducted the experiments. In the laboratory, we placed specimens in a IPP 30 Peltier Memmert climatic chamber, each specimen in individual Petri dish, and acclimated them for one day at the temperature of the cave. Air humidity was kept at $100 \%$ during the acclimation and during the experiments, by placing two Petri dishes filled with water inside the climatic chamber. During acclimation, small insects collected on the cave walls during sampling were offered ad libitum to each specimen tested. Owing to the high resistance to starvation of subterranean spiders (Mammola \& Isaia, 2017), specimens were not fed throughout the experiments.

For each sampled cave, we derived the internal mean annual temperature from continuous temperature measurements taken between 2012 and 2013 (Mammola et al., 2018b), or unpublished temperature records taken via the same methodology (Grotte della Maissa). For two caves lacking field-collected temperature records (indicated with an asterisk in Table 1), we downloaded annual temperature series from the same period from the nearest thermo-hygro-pluviometric weather station. After correcting the data with the standard environmental lapse rate $\left(0.57^{\circ} \mathrm{C} / 100 \mathrm{~m}\right.$; Rubel, Brugger, Haslinger, \& Auer, 2017), we calculated the mean annual temperature and used this value as a direct proxy of the cave temperature (Badino, 2010; Sánchez-Fernández et al., 2018).

We conducted experiments to determine the upper critical temperature with the climatic chamber, starting from the mean annual cave temperature, with an increasing slow temperature rate of $1^{\circ} \mathrm{C} /$ day. We evaluated the individual critical temperature $(\mathrm{CT})$ as the total paralysis, that is the temperature at which the individual was immobile and no appendage movements were visible (Le Lann et al., 2011). We observed that after the 
heating process, the spiders never recovered after being removed from the climatic chamber, a typical pattern when the temperature at which heat stupor occurs is close to the lethal temperature $\left(\mathrm{Wu} \&\right.$ Wright 2015). We expressed the $\mathrm{CT}_{50}$ as the measure of temperature at which $50 \%$ individuals experienced total paralysis. The experiment continued until all the specimens had stopped moving $\left(\mathrm{CT}_{100}\right)$. For each species tested, we kept approximately $10 \%$ of the specimens as controls in stable climatic conditions, to exclude the confounding effect of causes of mortality other than temperature alteration (e.g., starvation, stress). No mortality was recorded in controls during the experiments.

After the experiments we sexed each specimen (male, female or juvenile), confirmed species identity under a stereomicroscope, and acquired morphological measures to quantify the degree of subterranean specialization.

\section{Morphological measures}

For estimating the degree of subterranean specialization of each species tested, we measured three morphological traits, namely leg elongation (sum of leg I articles divided by body size), eye regression (sum of eye diameter divided by length of the ocular area) and profile reduction (cephalothorax height divided by cephalothorax width). The reliability of these measures to represent specialization to deep subterranean habitats in Troglohyphantes species is provided in Mammola et al. (2018a). To standardize measurements and obtain comparable estimations, we considered only adult females in the estimation, thereby avoiding problems related to sexual size dimorphism. We acquired measures in millimeters $(\mathrm{mm})$ from digital pictures made with a Leica EC3 digital camera installed on a Leica M80 stereoscopic microscope (up to 60x magnification), and with the Leica LAS EZ 3.0 software (Leica Microsystems, Switzerland).

\section{Elevational range extent and realized thermal niche breadth}


We assembled a database of occurrence localities of each Western alpine Troglohyphantes species, using recent literature geo-referenced records (Isaia et al., 2017; Mammola, Isaia, \& Arnedo, 2015; Mammola et al., 2018a, 2018b) (Fig. 1). We overlaid elevation and mean annual temperature rasters at 30 arcsec resolution (1970-2000; Fick \& Hijmans, 2017) to the occurrence records of each species. We calculated the elevational range as the difference between maximum and minimum elevations and the realized thermal niche breadth as the difference between maximum and minimum temperatures experienced by each species across its localities.

\section{Statistical analyses}

All statistical analyses were conducted using R software (R Core Team, 2017). We used the internal mean annual temperature of the caves as the baseline to calculate the delta with the species critical temperatures $(\Delta T$, a measure of thermal tolerance expressed as the difference between the CT and the mean temperature of the natural habitat of each specimen). We tested for differences in $\Delta T$ s between sexes (males, females or juveniles) with separate ANOVA, via the formula (R notation):

$$
\Delta \mathrm{T} \sim \text { sex }^{*} \text { species }
$$

For the four species collected in multiple caves (T. konradi, T. lucifer, T. lucifuga, T. vignal), we also used separate ANOVA to test for differences in $\Delta T$ s across populations and taking into account the sex, via the formula:

$$
\Delta \mathrm{T}(\text { species }) \sim \text { cave }+ \text { sex }
$$

We constructed standard survival curves with binomial Generalized Linear Models (GLM), whereby we modeled the percentage survival rate of each species as a function of $\Delta T$ (response variable). 
We performed a cluster analysis for grouping Troglohyphantes species into homogeneous classes of subterranean specialization, using the morphological traits measured on adult females. Using standardized values of traits, we estimated clusters via Euclidean distances and the Ward2's hierarchical clustering method (Murtagh \& Legendre, 2014), with the R package 'fastcluster' (Müllner, 2013). We relied on the Gap statistic for determining the optimal number of clusters k (Tibshirani, Walther, \& Hastie, 2001), allowing for a maximum $\mathrm{k}$ equal to the number of species tested and performing 500 bootstraps.

To verify if the shape of the survival curves varied in response to the degree of subterranean specialization of each species, we modeled the survival rate of all individuals tested as a function of $\Delta \mathrm{T}$ in interaction with the class of subterranean specialization, with a binomial Generalized Linear Mixed Model (GLMM) The mixed part of the model was designed to account for data dependence, using species identity as random factor. We fitted the models in R package 'Ime4' (Bates, Mächler, Bolker, \& Walker, 2015), with the formula:

$$
\text { Survival rate } \sim \Delta T^{*} \text { Class of subterranean specialization }+ \text { random factor (Species) }
$$

We tested the relationships between $\Delta \mathrm{T}$ and both the elevational range and the realized thermal niche breadth of each species with Phylogenetic Generalized Least Squares (PGLS) models, hence accounting for phylogenetic non-independence among species. We introduced the latest Troglohyphantes phylogeny (Mammola et al., 2018a) into the PGLSs via a Pagel correlation structure, with the R package 'nlme' (Pinheiro et al., 2017). Prior to this analysis, $\Delta T$ was log-transformed to account for one outlying observation ( $T$. lucifer). We tested for differences in elevation range extent and realized thermal niche breadth between species belonging to different classes of subterranean specialization with ANOVA.

The use of annual mean temperature to calculate $\Delta T$ may bias results for low specialized species because air temperature can vary substantially across seasons in . 
superficial cave sectors (Fig. 2). Therefore, we explored whether the results of our analysis would change if we computed $\Delta T$ using the cave temperature values at the time when the specimens were collected in the caves, rather than the mean annual cave temperaturte (Appendix S1 in Supporting Information).

Table 1. Overview of the species of Troglohyphantes tested and summary statistics. Cave [cadastre code] (Coordinates)= sampling locality, cadastre code in square brackets ("Art." denotes artificial sites) and approximate geographic coordinates in WGS84 decimal degrees; CaveT= mean annual temperature of the sampling locality; Spec.= subterranean specialization according to the cluster analysis; $\mathrm{n}=$ number of specimens tested (controls are included in the count); $\mathrm{CT}_{50 / 100}=$ temperature at which $50 \%$ or $100 \%$ individuals experienced total paralysis; $\Delta T_{50 / 100}=$ temperature at which $50 \%$ or $100 \%$ individuals experienced total paralysis relative to the mean annual cave temperature at which the specimens were sampled.

\section{Cave}

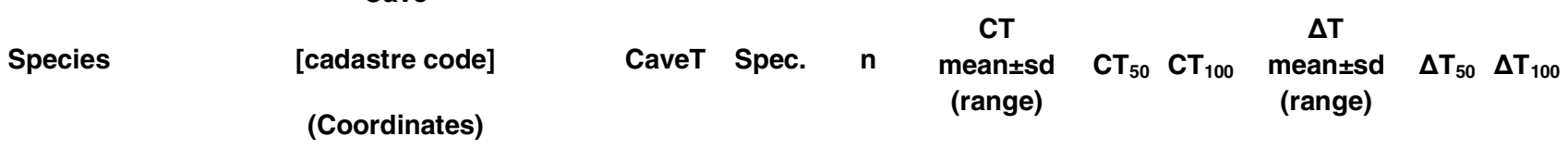

Grotte della Maissa

[Pi 1214, 1215, 1219]

8.5

T. konradi

$(44.26 \mathrm{~N}, 7.40 \mathrm{E})$

Brignoli

Sotterranei di Vernante [Art.]

(44.25 N, 7.52 E)

Grotta delle Arenarie

T. lanai

[Pi 2509]

9.

Isaia \& Pantini

$(45.71 \mathrm{~N}, 8.31 \mathrm{E})$

Grotta di Bossea

T. pedemontanus Gozo

[Pi 108]

8.9

High $\quad 15$

$11.88 \pm 0.96$

(10.5-13.5)

13

14

$3.38 \pm 0.96$

(2-5)

$.92 \pm 1.23$
$(1-5)$

1

5

(44.24 N, 7.84 E)

Grotte di Pugnetto

T. bornensis

[Pi 1501-1504]

Isaia \& Pantini

(45.27 N, 7.14 E)

$9.44 \pm 0.73$
$(9-11)$

9

11

$0.94 \pm 0.73$

(0.5-2.5)
1

3 


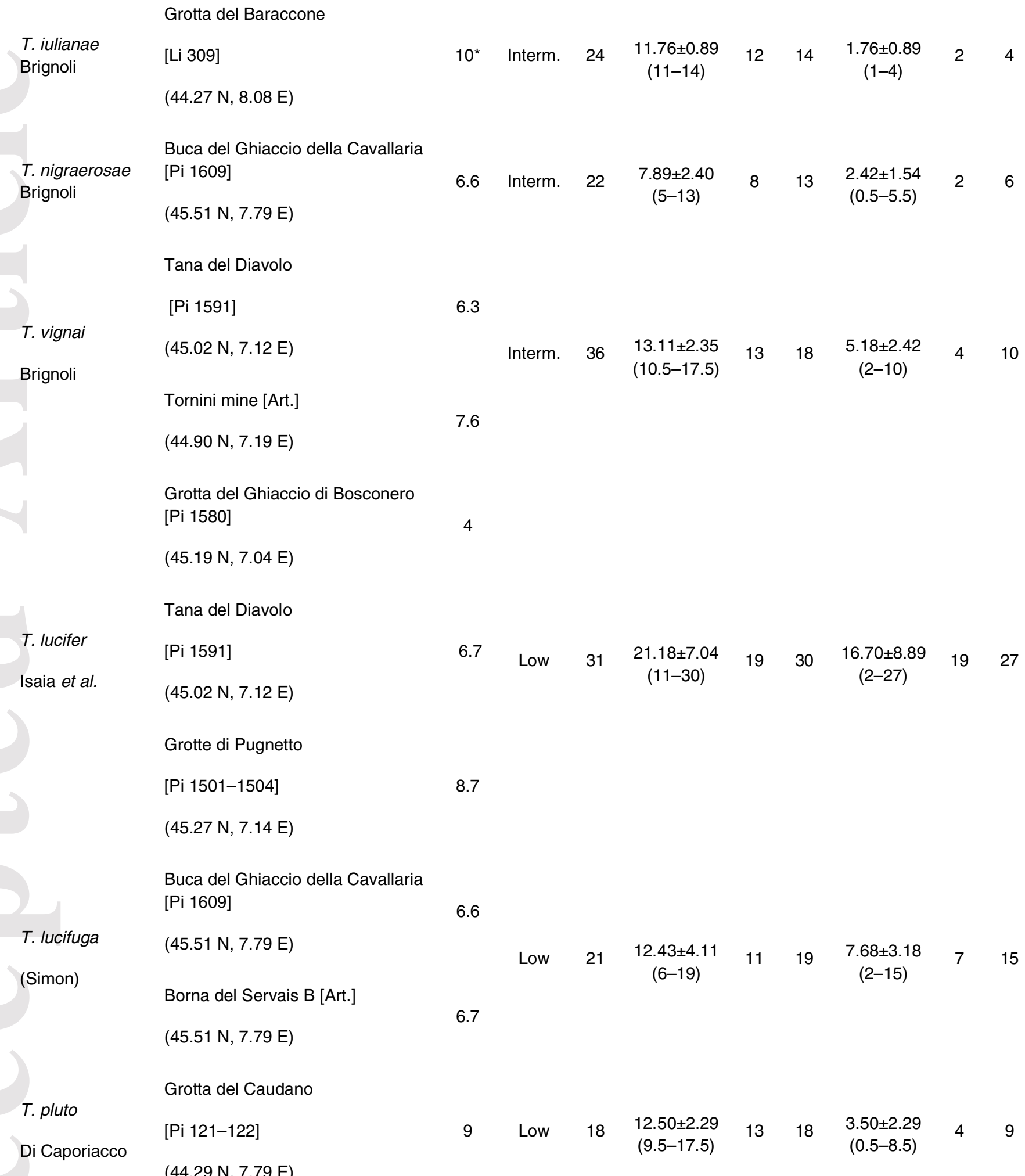

* Internal mean annual temperature estimated from the closest weather station 


\section{RESULTS}

\section{Thermal overlap for deep and shallow cave habitats}

Variation in ambient temperature was extremely low in deep sectors of caves, with virtually no detectable daily variations and seasonal variations in the order of one tenth of degree. We observed no overlap in thermal regimes between deep caves habitats at different elevations (Fig. 2B). By contrast, thermal regimes were more variable in the superficial cave sectors and there was a substantial overlap between thermal regimes among these habitats at different elevations (Fig. 2A).

\section{Experimental test on thermal tolerance}

A total of 247 specimens belonging to 11 species were collected in 13 caves across the Western Italian Alps. The species T. bolognai was excluded from the analysis, because high mortality of individuals occurred during the acclimation phase before the beginning of the test. All remaining species were successfully tested in the climatic chamber (Table 1 ). Narrow thermal tolerance was observed for most Troglohyphantes (Fig. 3A), with the majority of species reaching their $\mathrm{CT}_{50}$ at $\Delta \mathrm{T}$ ranging from 1 to $4{ }^{\circ} \mathrm{C}$ (Table 1 ). $T$. bornensis and $T$. konradi proved to be the least tolerant species, reaching their $\mathrm{CT}_{50}$ at $\Delta \mathrm{T}$ of $1{ }^{\circ} \mathrm{C}$, and its $\mathrm{CT}_{100}$ at $\Delta \mathrm{T}$ ranging from 3 and $5{ }^{\circ} \mathrm{C}$, respectively. Conversely, $T$. lucifer was the most tolerant species, reaching its $\mathrm{CT}_{50}$ at $\Delta \mathrm{T} 19^{\circ} \mathrm{C}$ and its $\mathrm{CT}_{100}$ at $27^{\circ} \mathrm{C}$.

For all species tested, $\Delta \mathrm{T}$ did not significantly varied depending on the sex of the specimens (ANOVA: $F_{18,152}=0.31, \mathrm{p}=0.99$ ). In the case of three species ( $T$. lucifuga, $T$. vignai, T. konradi) for which we tested two populations, no differences in $\Delta T$ between populations (ANOVA: T. konradi: $F_{2,21}=0.81, p=0.46 ;$. lucifuga: $F_{2,10}=3.45, p=0.09 ; T$. vignai: $\left.F_{2,24}=1.65, \mathrm{p}=0.21\right)$ were detected. In the case of $T$. lucifer, most individuals were collected in one out of the three caves (Grotta del Ghiaccio di Bosconero), preventing to fit a robust ANOVA due to a significant imbalance in the levels of the factor. Also, we found no . 
effects of sex and population on $\Delta \mathrm{T}$ when we estimated $\Delta \mathrm{T}$ using the cave temperature values at the time when the specimens were collected in the caves (Appendix S1).

\section{Subterranean habitat specialization}

Using morphological traits and a Ward2 hierarchical clustering method, we assigned each species to a distinct class of subterranean specialization. The Gap statistic revealed an optimal $\mathrm{k}$ of 3 , corresponding to three discrete classes of species with similar levels of morphological subterranean specialization (Fig. 4). The first cluster included all individuals belonging to $T$. lucifer, T. lucifuga and $T$. pluto, namely species with minor morphological specialization to subterranean life (eyes normally developed and abdominal pattern present) and often found in the vicinity of the cave entrance or in shallow subterranean habitats ("Low" class of subterranean specialization in Fig. 4). The second cluster comprised species with a moderate degree of morphological specialization ("Intermediate" class in Fig. 4), and included most individuals of the species $T$. bornensis, $T$. iulianae, $T$. nigraerosae and $T$. vignai. The third cluster comprised highly specialized species ("High" class in Fig. 4), namely T. konradi, T. lanai and T. pedemontanus, with pronounced eye and profile reduction, appendage elongation and absence of abdominal pigmentation. Clusters were mostly homogeneous, with the exception of six misplaced individuals highlighted in Fig. 4.

\section{Relationship between thermal tolerance, specialization and elevational range}

GLMM revealed a significant interaction between $\Delta T$ and the class of specialization, indicating that the shape of the survival curve varied according to the degree of subterranean habitat specialization (Fig. 3B; see also Fig. S1). The high and intermediate class curves were significantly different from the low one (GLMM: High: estimated $\beta \pm S E=-$ $1.43 \pm 0.19, p$-value $<0.01$; Intermediate: estimated $\beta \pm S E=-0.68 \pm 0.07, p<0.01$ ), indicating a 
steep decline in survival rate at increasing $\Delta \mathrm{T}$. Conversely, the survival curve for low specialized Troglohyphantes declined more smoothly (Low: estimated $\beta \pm S E 2.60 \pm 0.84$ ).

We found a significant positive relationship between a species' elevational range and thermal tolerance $(\Delta T)$, with increasing elevational range extents at increasing values of $\Delta T$ (Fig. 3C; PGLS: estimated $\beta \pm S E=930.06 \pm 184.66, p<0.01$ ) and no phylogenetic signal in the residuals (Pagel $\lambda=-0.71$ ). The extent of a species' elevational range decreased significantly with increasing specialization to deep subterranean life (Fig. 3D; ANOVA: $F_{2,8}=$ $5.47, p<0.05)$. We recovered the same significant trend with respect to the realized thermal niche breadth, with increasing variation in temperature among localities of a species' range at increasing values of $\Delta T$ (Fig. 3E; PGLS: estimated $\beta \pm S E=4.02 \pm 0.92, p<0.01$; Pagel $\lambda=-$ 0.31). Furthermore, realized thermal niche breadth decreased significantly with increasing specialization to deep subterranean life (Fig. $3 F ; F_{2,8}=4.61, p<0.05$ ).
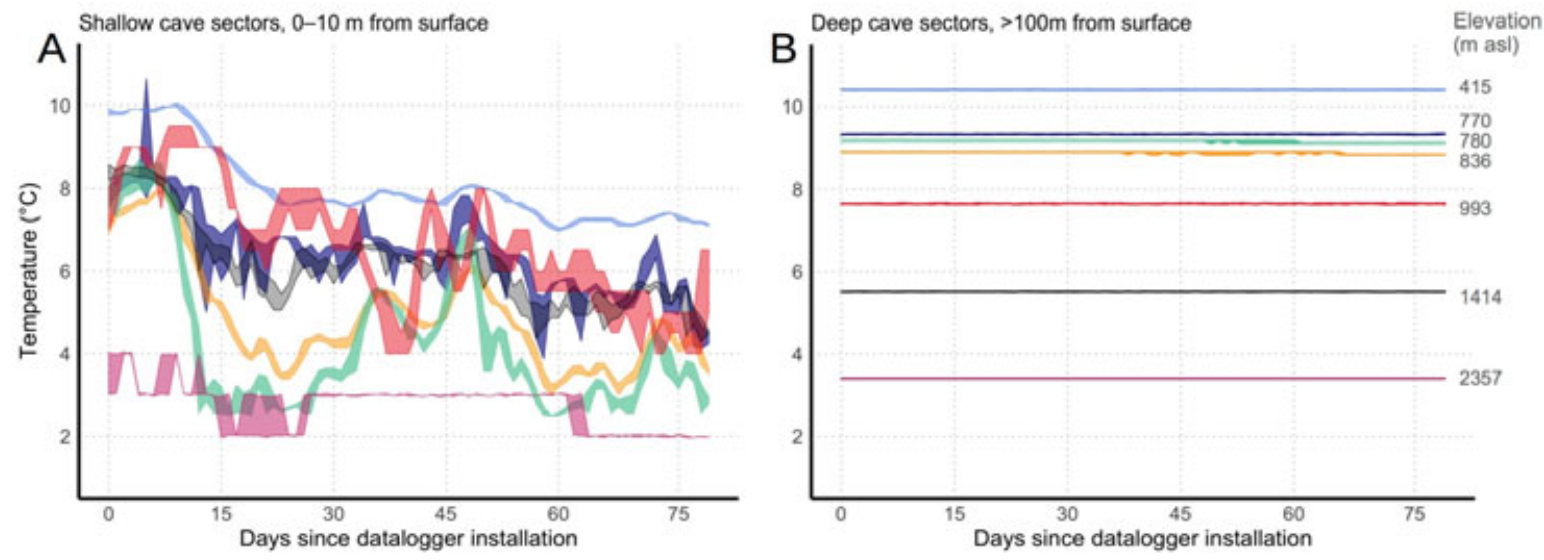

Figure 2. Compared to shallow cave habitats (A), deep cave habitats show extremely reduced thermal seasonality and no overlap in thermal regimes across elevational gradient (B). Seasonal experimental temperature records shown in the graph were taken in winter (20 Nov $2012-04$ Feb 2013) across caves at different elevations in the Western Italian Alps, using Hygrochron ${ }^{\mathrm{TM}}$ 
dataloggers installed at the cave entrance (1-10 $\mathrm{m}$ from surface) and deeper inside the cave (>100 m from surface). Daily temperature range (max-min) is shown. Same color corresponds to same cave.
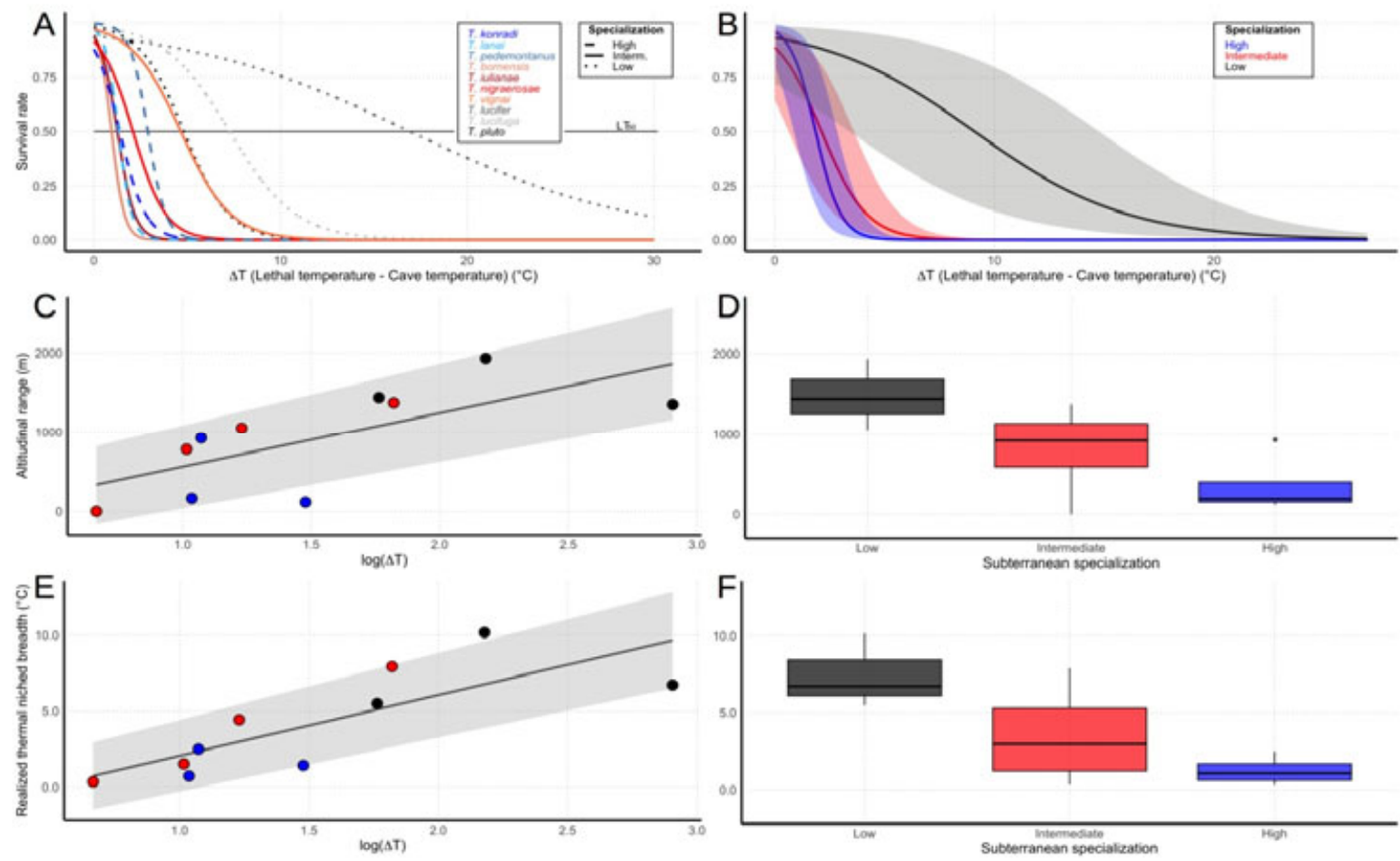

Figure 3. Thermal tolerance $(\Delta \mathrm{T})$ of Western alpine Troglohyphantes species according to the class of subterranean specialization, and relations with elevational range extent and realized thermal niche breadth. A) Survival rate as a function of $\Delta T$. Survival curves represent best fits to the data, according to GLMs. B) Predicted relationship between the survival rate of Troglohyphantes species and $\Delta \mathrm{T}$, in interaction with the class of morphological adaptation to the subterranean conditions, as derived from GLMM. C) Relationship between elevational range extent and $\Delta T$, according to PGLS. D) Differences in the extent of elevational range among the three classes of morphological specialization to subterranean life. E) Relationship between the thermal breadth experienced by species across their elevational range and $\Delta \mathrm{T}$, according to PGLS. F) Differences in realized thermal breadth among classes of morphological specialization to subterranean life. Color coding in $\mathbf{C}-\mathbf{F}$ refers to the legend in the inset $\mathbf{B}$. 

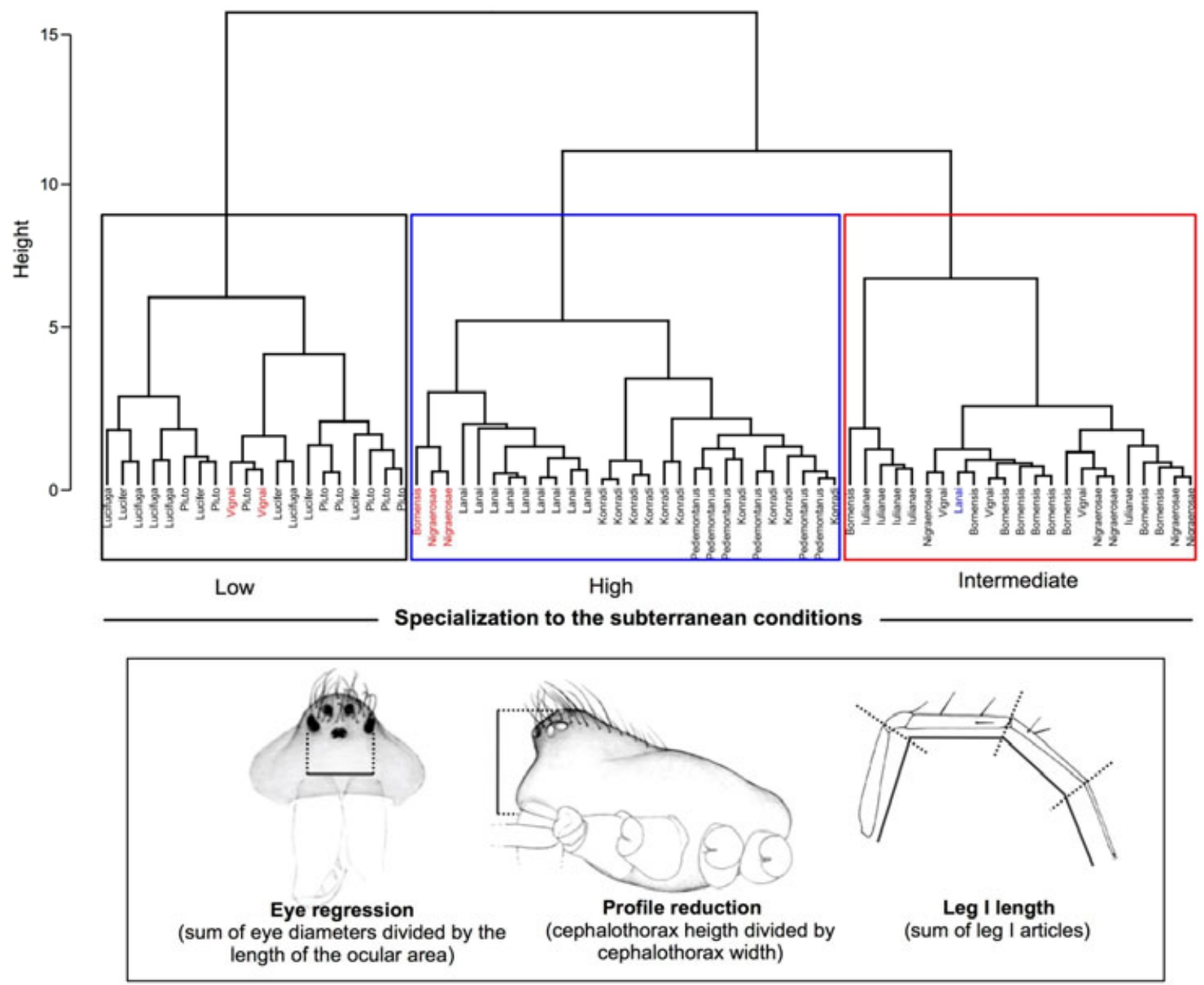

Figure 4. Overall morphological similarity among the Troglohyphantes species considered in the analyses. Clustering is based on three morphological traits (bottom panel) and on Euclidean distances and Ward2's hierarchical clustering. Three distinct clusters correspond to the three classes of subterranean specialization: low ( $T$. lucifuga, T. lucifer, $T$. pluto), intermediate ( $T$. bornensis, $T$. nigraerosae, $T$. vignal), and high ( $T$. konradi, $T$. lanai, $T$. pedemontanus) specialized species. Misplaced individuals are highlighted with the color of their putative cluster. Morphological drawings by Elena Pelizzoli. 


\section{DISCUSSION}

\section{Extending Janzen's hypothesis to temperate subterranean ecosystems}

Five decades after its publication, Janzen's (1967) milestone contribution has been listed among the 100 most influential papers in ecology (Courchamp \& Bradshaw, 2018). The mountain passes hypothesis is seminal not only in providing a mechanistic explanation for biodiversity patterns in tropical versus temperate mountain systems (Ghalambor et al., 2006; Sheldon et al, 2018), but also because it can potentially be transferred to a large variety of habitats displaying steep gradients of thermal seasonality, including for example soils (Bahrndorff, Loeschcke, Pertoldi, Beier, \& Holmstrup, 2009; Raschmanová, Miklisová, Kováč, \& Šustr, 2015), polar waters (Peck, Webb, \& Bailey, 2004; Pörtner, Peck, \& Somero, 2007), and deep sea (Rex et al., 1993). Yet, the ecological complexity of most ecosystems and the challenge posed by the geographic scale at which this hypothesis can be tested, have largely prevented ecologists from comprehensively testing the underlying assumptions of Janzen's hypothesis and transferring it to non-tropical settings (Gill et al., 2016; McCain, 2009; Polato et al., 2018; Scheffers et al., 2017). Due to their ecological simplicity and environmental stability, subterranean habitats emerge as an ideal model system in which to explore eco-evolutionary questions in general (Mammola, 2018; Sánchez-Fernández et al., 2018) and hypotheses pertaining to thermal niche breadth in particular (Eme et al., 2014; Mermillod-Blondin et al., 2013; Pallarés et al., 2019; Raschmanová et al., 2018; Rizzo, Sánchez-Fernández, Fresneda, Cieslak, \& Ribera, 2015).

Our extension of Janzen's mountain passes hypothesis to temperate subterranean ecosystems is based on the integration of multiple lines of evidence and is grounded in organismal and habitat measures. Rather than inferring thermal tolerance breadth from species distributions (see Cardillo, Dinnage, \& McAlister, 2019), we quantified thermal traits via experimental tests on the widest simultaneous set of congeneric subterranean organisms to date (Fig. 3A). We also used annual temperature data series measured at the habitat level, that allowed us to characterize the steep gradients of thermal variability in caves (Fig. . 
2). An additional novelty of this study was to use a quantitative method supported by statistical inference to estimate the level of subterranean specialization of the different species (Fig. 4), and to incorporate this information in the evaluation of the thermal tolerance (Fig. 3B).

\section{Thermal tolerance and subterranean specialization}

By integrating morphological measures and physiological experiments, we were first able to demonstrate that an increased specialization to subterranean habitats was accompanied by a concomitant reduction in thermal tolerance. Overall, intermediate and highly subterranean specialized Troglohyphantes species reached $\mathrm{CT}_{50}$ already between 1 and $4{ }^{\circ} \mathrm{C}$ above their natural ambient temperature, and $\mathrm{CT}_{100}$ between 3 and $10^{\circ} \mathrm{C}$. Within the intermediate class of specialization, $T$. vignai was the only species to exhibit a greater thermal tolerance. In particular, the species behaved similarly to T. pluto, which clustered in the low specialized class (Fig. 4). In this regard, it is worth noting that populations of $T$. vignai display a high genetic structuring (Mammola et al., 2015), which casts some doubts about the current taxonomic status of this species and, consequently, about its thermal tolerance limits. The low specialized species T. lucifuga and T. lucifer, showed the widest thermal tolerances, reaching $\mathrm{CT}_{50}$ at 7 and $19{ }^{\circ} \mathrm{C}$ above their natural ambient temperature, respectively, and $\mathrm{CT}_{100}$ at 15 and $27^{\circ} \mathrm{C}$. In other words, species that are morphologically specialized for life in shallow subterranean habitats proved to be able to withstand a two-fold larger temperature increase than species morphologically specialized for life in deep subterranean habitats. This result is consistent with the fact that the seasonal variability of shallow subterranean habitats is much greater than that of deep subterranean habitats (Pipan et al., 2011).

PGLS analyses revealed a weak phylogenetic signal in our dataset, implying that two closely related Troglohyphantes species are not necessarily more physiologically similar than two Troglohyphantes species selected at random from the phylogenetic tree. This result . 
probably owed much to our study's specificity which consisted in using a regional scale for testing Janzen's hypothesis. Using species from temperate and tropical regions, species within these two regions are more closely related to each other and they display similar physiological traits; hence the strong phylogenetic signal typically observed in a number of studies (Gutiérrez-Pesquera et al., 2016). Conversely, when using multiple congeneric species from the same region but specialized to different habitats-in our case, deep and shallow subterranean habitats-there is a greater chance that some species from the most climatically-variable habitat evolved species adapted to the more climatically-stable one. This yields sister species exhibiting contrasted thermal tolerance, hence the weak phylogenetic signal observed in our study.

\section{Subterranean specialization and elevational range extent}

Having adapted to narrow thermal conditions (Fig. 2B), specialized subterranean organisms would have more difficulty in crossing topographic barriers than less specialized species, because they would be more likely to encounter temperatures outside their thermal tolerance (Ghalambor et al., 2006). In the alpine context in which Troglohyphantes species are found, subterranean dispersal over elevational gradients would be unlikely, in account for the significant variation in temperature and reduced overlap in thermal regime between deep cave habitats at different elevations (Fig. 2B; Rubel et al., 2017). The small-range size of subterranean species has long been solely attributed to habitat fragmentation (e.g. Christman \& Culver, 2001; Moldovan, Meleg, \& Perşoiu, 2012), without considering the potential influence of thermal specialization on dispersal propensity (Eme et al., 2014). Yet, this study is the first to establish a relationship between the extent of a subterranean species' range across the elevation gradient and its thermal tolerance. Habitat fragmentation and thermal specialization most likely act synergistically to constrain dispersal. Habitat 
fragmentation restricts maladaptive gene flow between populations, thereby facilitating thermal specialization, which itself creates physiological barriers to dispersal.

A potentially important caveat of the present study is the use of range size as a surrogate for dispersal capacity (Lester, Ruttenberg, Gaines, \& Kinlan, 2007). Yet, there are several lines of evidence which suggest that dispersal within the genus Troglohyphantes indeed depends on the degree of subterranean specialization. In $T$. vignai, the only specialized species of Troglohyphantes for which a population genetic study was carried out, mitochondrial and nuclear genetic data at the population/species interface indicated very limited gene flow, with many populations being strongly isolated from each other (Mammola et al., 2015). Furthermore, widely distributed species like T. lucifuga, but also other low subterranean specialized Troglohyphantes species distributed in central and eastern Alps, are typically found both in caves and more superficial habitats, including deep leaf litter strata, voids in rocky debris, and other moist and shaded retreats (Isaia et al., 2017; Mammola et al., 2018a, 2018b). This ecological plasticity would enhance dispersal across shallow habitats and would explain their larger distribution ranges (Mammola et al., 2015). Conversely, specialized and short-ranged species of Troglohyphantes are almost exclusively collected in caves, empirically suggesting a reduced capacity to disperse through nonsubterranean habitats (Isaia et al., 2017).

Our extension of Janzen's hypothesis to subterranean habitat also provides a potential mechanism for explaining the high rate of local endemism and increased species packing that are typically observed in disparate subterranean systems (e.g. Hedin, 2015; Njunjić et al., 2018; Ribera et al., 2010; Wessel et al., 2013). It is acknowledged that strong topographic heterogeneity could both inflate speciation rate by increasing specialization and imposing barriers to dispersal, and decrease the extinction rate by promoting local survival during climate shifts (Jetz \& Rahbek, 2002; Ohlemüller et al., 2008; Eme et al., 2014). In the case of our model organisms, the specialization to a habitat with limited seasonal variability may have contributed to promote reproductive isolation, leading to high adaptive radiation in . 
the genus and to a high proportion of small-range endemics, even co-occurring within limited geographic extents (Isaia et al., 2017; Mammola et al., 2018a). In the Western Alps as much as six closely related species are known to coexist in the district of Alpi Liguri, i.e. just about $3,000 \mathrm{~km}^{2}$ (Fig. 1). Yet, the occurrence of non-overlapping thermal regimes among deep subterranean habitats at different elevations and the very narrow thermal tolerance of specialized subterranean species question the idea that sharp elevational climatic gradients may favor local survival through short distance dispersal during climate shifts.

\section{Climatic controls on subterranean biodiversity patterns}

Our findings contribute to reconcile contrasted views about the relative importance of two distinct scales of climate variability in shaping patterns of subterranean biodiversity (Zagmajster et al., 2014), a topic that has been recently discussed also in surface ecosystems (Scheffers \& Williams, 2018; Scheffers et al., 2017). Using correlative methods, Zagmajster et al. (2014) and Eme et al. (2018) showed that long-term temperature variability accounted for a substantial variation in range size of groundwater crustaceans across Europe. Yet, the lack of latitudinal variation in temperature seasonality in subterranean habitats does not necessarily imply that the observed pattern of increasing range at higher latitudes is primarily driven by climatic variability acting at much longer time-scales than the seasonal scale. If, as pointed out by the results of this study, the absence of thermal seasonality drives subterranean species towards narrow thermal specialization and low dispersal capacity, then these species are also less likely to survive major climate change and to recolonize vacant areas once climate becomes favorable again. The two temporal scales of climate variability might have acted in concert to shape the current distribution of Troglohyphantes species in the Western Alps. On the one hand, all specialized subterranean Troglohyphantes species occur in areas that were free of ice during the Pleistocene (Mammola et al., 2018b: p. 237, fig. 2), which is consistent with a scenario of restricted 
dispersal following the retreat of Pleistocene glaciers. On the other hand, the distribution range of low specialized species, especially $T$. lucifuga, stretches in areas that were entirely covered by the primary ice shield during the Pleistocene, which could be explained by the species having colonized the area in recent time, after the glaciers retreated (Mammola et al., 2018b).

Our study has also important implications for determining the vulnerability of subterranean species to anthropogenic climate change. Climate change is expected to affect deep subterranean habitats (Mammola et al., 2019; Taylor et al., 2013), especially by increasing ambient temperature and reducing moisture content, although with a certain delay due to the thermal inertia of the rock (Mammola et al., 2019). In this context, the likelihood of evolutionary responses will depend on the magnitude and rates of warming within subterranean habitats. To date, the few available studies attempting to predict the future response of subterranean species to altered climatic conditions were based on correlative species distribution models (SDM) projected onto future climate change scenarios (Mammola \& Leroy, 2018). However, such predictions may be unreliable if species display greater thermal tolerance than those reflected by their current geographic ranges (SánchezFernández et al., 2016). Results of the present study suggest that the ecological specialization-dispersal tradeoff prevents specialized subterranean species from exploiting regions with uncertain climates, a proposal which is entirely consistent with previous SDM forecasts of habitat quality for Troglohyphantes spp. both in the Pleistocene and under future climate change scenarios (Mammola et al., 2018b). By considering the results of this study in the light of these future habitat change projections, we can predict that most specialized subterranean species will unlikely be able to overcome climatic alterations by means of dispersal. However, we observed variability in the individual response to increasing temperature among the tested populations, with some individuals being able to withstand greater temperature increases in respect to the population average (Table 1). On a positive note, this variability suggests that more tolerant individuals may possibly undergo selection 
of key physiological traits in a climate change scenario, resulting in phenomena of local adaptation and in situ persistence.

Concerns over the fate of biodiversity in a changing climate have revived biodiversity research into Janzen's thoughts (Sheldon et al., 2018). By extending Janzen's hypothesis to climatically-stable habitats other than tropical mountains, we pave the way for integrating the ecological specialization/dispersal tradeoff into understanding the differential responses of species to climate instability across a broad range of ecosystems. Ultimately, our contribution shows that the "move or adapt" dilemma in response to climate change (Nogués-Bravo et al., 2018) may in part already be set by the specialization/dispersal tradeoff. Therefore, we encourage scientists to take into consideration physiological barriers to dispersal into their modelling fitting exercises, when predicting the species response to climate change.

\section{ACKNOWLEDGEMENTS}

This work was funded by University of Turin and Compagnia di San Paolo (Grant Award: CSTO162355). FM was supported by grants from the French programs STYGOMICS (CNRS Défi Enviromics), CONVERGENOMICS (no. ANR-15-CE32-0005) and EUR H2O'Lyon (ANR-17-EURE-0018). A special thanks goes to Alexandra Jones for assistance in the laboratory and to Andrea John Dejanaz for carrying out morphological measures; to Filippo Milano, Nicolò Chiappetta and Raffaella Zerbetto for fieldwork assistance; Yael Lubin for proof-reading our English and useful comments; and two anonymous reviewers for their constructive comments.

\section{Author contributions statement:}

$\mathrm{SM}, \mathrm{MI}$ and EP conceived the idea and designed methodology; . 
FM provided the hypothesis framework and eco-evolutionary arguments;

PV provided ecophysiological arguments;

SM and MI performed fieldwork;

SM and EP analyzed the data;

SM led the writing of the manuscript;

All authors contributed critically to the drafts and gave final approval for publication.

Disclosure statement: The authors report no conflicts of interest.

Data accessibility statement: Data supporting this study are available in Figshare (doi:10.6084/m9.figshare.8058302) [the link will become available upon acceptance]

\section{REFERENCES}

Badino, G. (2010). Underground meteorology. What's the weather underground? Acta Carsologica, 39, 427-448. doi:10.3986/ac.v39i3.74

Bahrndorff, S., Loeschcke, V., Pertoldi, C., Beier, C., \& Holmstrup, M. (2009). The rapid cold hardening response of Collembola is influenced by thermal variability of the habitat. Functional Ecology, 23, 340-347. doi:10.1111/j.1365-2435.2008.01503.x

Bates, D., Mächler, M., Bolker, B., Walker, S. (2015). Fitting linear mixed-effects models using Ime4. Journal of Statistical Software, 67, 1-48. doi:10.18637/jss.v067.i01

Cardillo, M., Dinnage, R., \& McAlister, W. (2019). The relationship between environmental niche breadth and geographic range size across plant species. Journal of Biogeography, 46, 97-109. doi: $10.1111 /$ jbi. 13477

Christman, M. C., \& Culver, D. C. 2001. The relationship between cave biodiversity and available habitat. Journal of Biogeography, 28, 367-380. doi:10.1046/j.1365-2699.2001.00549.x

Cigna, A. A. (2002). Modern trend(s) in cave monitoring. Acta Carsologica, 31, 35-54. doi:10.3986/ac.v31i1.402 
Courchamp, F., \& Bradshaw, C. J. A. (2018). 100 articles every ecologist should read. Nature Ecology \& Evolution, 2, 395-401. doi:10.1038/nature.2016.20987

Deutsch, C. A., Tewksbury, J. J., Huey, R. B., Sheldon, K. S., Ghalambor, C. K., Haak, D. C., \& Martin P. R. (2008). Impacts of climate warming on terrestrial ectotherms across latitude. Proceedings of the National Academy of Sciences, 105(18), 6668--6672. doi:10.1073/pnas.0709472105

Eme, D., Malard, F., Colson-Proch, C., Jean, P., Calvignac, S., Konecny-Dupré, L., ... Douady, C. J. (2014). Integrating phylogeography, physiology and habitat modelling to explore species range determinants. Journal of Biogeography, 41, 687-699. doi:10.1111/jbi.12237

Eme, D., Zagmajster, M., Delić, T., Fišer, C., Flot, J. F., Konecny-Dupré, L., ... Malard, F. (2018). Do cryptic species matter in macroecology? Sequencing European groundwater crustaceans yields smaller ranges but does not challenge biodiversity determinants. Ecography, 41, 424-436. doi:10.1111/ecog. 02683

Fick, S. E., \& Hijmans, R. J. (2017). Worldclim 2: New 1-km spatial resolution climate surfaces for global land areas. International Journal of Climatology, 37, 4302-4315. doi:10.1002/joc.5086

Ghalambor, C. K., Huey, R. B., Martin, P. R., Tewksbury, J. J., \& Wang, G. (2006). Are mountain passes higher in the tropics? Janzen's hypothesis revisited. Integrative Comparative Biology, 46, 517. doi:10.1093/icb/icj003

Gill, B. A., Kondratieff, B. C., Casner, K. L., Encalada, A. C., Flecker, A. S., Gannon, D. G., ... Thomas, S. A. (2016). Cryptic species diversity reveals biogeographic support for the 'mountain passes are higher in the tropics' hypothesis. Proceeding of The Royal Society B: Biological Sciences, 283, 20160553. doi:10.1098/rspb.2016.0553

Gutiérrez-Pesquera, L. M., Tejedo, M., Olalla-Tárraga, M. Á., Duarte, H., Nicieza, A., \& Solé M. (2016). Testing the climate variability hypothesis in thermal tolerance limits of tropical and temperate tadpoles. Journal of Biogeography, 43, 1166-1178. doi:10.1111/jbi.12700

Hedin, M. (2015). High-stakes species delimitation in eyeless cave spiders (Cicurina, Dictynidae, Araneae) from central Texas. Molecular Ecology, 24, 346-361. doi:10.1111/mec.13036

Isaia, M., Mammola, S., Mazzuca, P., Arnedo, M. A., \& Pantini, P. (2017). Advances in the systematics of the spider genus Troglohyphantes (Araneae, Linyphiidae). Systematics and Biodiversity, 15, 307-326. doi 10.1080/14772000.2016.1254304 
Jansson, R., \& Dynesius, M. (2002). The fate of clades in a world of recurrent climatic change: Milankovitch oscillations and evolution. Annual Review of Ecology and Systematics, 33, 741- 777. doi:10.1146/annurev.ecolsys.33.010802.150520

Janzen, D. H. (1967). Why mountain passes are higher in the tropics. The American Naturalist, 101, 233-249.

Jetz, W., \& Rahbek, C. (2002). Geographic range size and determinants of avian species richness. Science, 297, 1548-51. doi:10.1126/science.1072779

Le Lann, C., Roux, O., Serain, N., Van Alphen, J. J., Vernon, P., Van Baaren, J. (2011). Thermal tolerance of sympatric hymenopteran parasitoid species: does it match seasonal activity?. Physiological Entomology, 36, 21-28. doi:10.1111/j.1365-3032.2010.00758.x

Lester, S. E., Ruttenberg, B. I., Gaines, S. D., \& Kinlan, B. P. (2007). The relationship between dispersal ability and geographic range size. Ecology Letters, 10, 745-758. doi:10.1111/j.14610248.2007.01070.x

Mammola, S. (2018) Finding answers in the dark: caves as models in ecology fifty years after Poulson and White. Ecography, 41, 1-21. doi: 10.1111/ecog.03905

Mammola, S. \& Leroy, B. (2018). Applying species distribution models to caves and other subterranean habitats. Ecography, 41, 1194-1208. doi:10.1111/ecog.03464

Mammola, S., Isaia, M., \& Arnedo, M. A. (2015). Alpine endemic spiders shed light on the origin and evolution of subterranean species. PeerJ, 3, e1384. doi:10.7717/peerj.1384

Mammola, S., Arnedo, M. A., Pantini, P., Plano, E., Chiappetta, N., \& Isaia, M. (2018a). Ecological speciation in darkness? Spatial niche partitioning in sibling subterranean spiders (Araneae: Linyphiidae: Troglohyphantes). Invertebrate Systematics, 32, 1069-1082. doi:10.1071/IS17090.

Mammola, S., Goodacre, S. L., \& Isaia, M. (2018b). Climate change may drive cave spiders to extinction. Ecography, 41, 233-243. doi:10.1111/ecog.02902

Mammola, S., Piano, E., Cardoso, P., Vernon, P., Domínguez-Villar, D., Culver, D. C., Pipan, T., \& Isaia, M. (2019). Climate change going deep: the effects of global climatic alterations on cave ecosystems. The Anthropocene Review, 00, 1-19. doi:10.1177/2053019619851594

Mermillod-Blondin, F., Lefour, C., Lalouette, L., Renault, D., Malard, F., Simon, L., \& Douady, C. J. (2013). Thermal tolerance breadths among groundwater crustaceans living in a thermally constant environment. Journal of Experimental Biology, 216, 1683-1694. doi:10.1242/jeb.081232 
McCain, C. M. (2009). Vertebrate range sizes indicate that mountains may be 'higher' in the tropics. Ecology Letters, 12, 550-560. doi:10.1111/j.1461-0248.2009.01308.x

Mittelbach, G. G., Schemske, D. W., Cornell, H. V., Allen, A. P., Brown, J. M., Bush, M. B., .. McCain, C. M. (2007). Evolution and the latitudinal diversity gradient: speciation, extinction and biogeography. Ecology Letters, 10, 315-331. doi:10.1111/j.1461-0248.2007.01020.x

Moldovan, O. T., Meleg, I. N., \& Perşoiu, A. (2012). Habitat fragmentation and its effects on groundwater populations. Ecohydrology, 5, 445-452. doi:10.1002/eco.237

Morueta-Holme, N., Enquist, B. J., McGill, B. J., Boyle, B., Jørgensen, P. M., Jeffrey, E. O., ... Svenning, J.-C. (2013). Habitat area and climate stability determine geographical variation in plant species range sizes. Ecology Letters, 16, 1446-1454. doi:10.1111/ele.12184

Müllner, D. (2013). fastcluster: fast hierarchical, agglomerative clustering routines for $R$ and Python. Journal of Statistical Software, 53, 1-18. doi:10.18637/jss.v053.i09

Muñoz, M. M., \& Bodensteiner, B. L. (2019). Janzen's hypothesis meets the Bogert effect: connecting climate variation, thermoregulatory behavior, and rates of physiological evolution. Integrative Organismal Biology, 1, oby002. doi:10.1093/iob/oby002

Murtagh, F., \& Legendre, P. (2014). Ward's hierarchical agglomerative clustering method: which algorithms implement Ward's criterion?. Journal of Classification, 31, 274-295. doi:10.1007/s00357014-9161-z

Nogués-Bravo, D., Rodríguez-Sánchez, F., Orsini, L., De Boer, E., Jansson, R., Morlon, H., ... \& Jackson, S. T. (2018). Cracking the code of biodiversity responses to past climate change. Trends in Ecology \& Evolution, 33, 765-776. doi:10.1016/j.tree.2018.07.005

Njunjić, I., Perrard, A., Hendriks, K., Schilthuizen, M., Perreau, M., Merckx, V., ... Deharveng, L. (2018). Comprehensive evolutionary analysis of the Anthroherpon radiation (Coleoptera, Leiodidae, Leptodirini). PloS ONE, 13(6), e0198367. doi:10.1371/journal.pone.0198367

Ohlemüller, R., Anderson, B. J., Araújo, M. B., Butchart, S. H., Kudrna, O., Ridgely, R. S., \& Thomas, C. D. (2008). The coincidence of climatic and species rarity: high risk to small-range species from climate change. Biology Letters, 4, 568-572. doi:10.1098/rsbl.2008.0097 
Pallarés, S., Colado, R., Pérez-Fernández, T., Wesener, T., Ribera, I., \& Sánchez-Fernández, D. (2019). Heat tolerance and acclimation capacity in unrelated subterranean arthropods living under common and stable thermal conditions. BioRxiv, 598458. doi:10.1101/598458

Peck, L. S., Webb, K. E., \& Bailey, D. M. (2004). Extreme sensitivity of biological function to temperature in Antarctic marine species. Functional Ecology, 18, 625-630. doi:10.1111/j.02698463.2004.00903.x

Pinheiro, J., Bates, D., DebRoy, S., Sarkar, D., \& R Core Team, (2017). nlme: Linear and Nonlinear Mixed Effects Models. R package version 3.1-131.

Pipan, T., López, H., Oromí, P., Polak, S., \& Culver, D. C. (2011). Temperature variation and the presence of troglobionts in terrestrial shallow subterranean habitats. Journal of Natural History, 45, 257-273. doi:10.1080/00222933.2010.523797

Polato, N. R., Gill, B. A., Shah, A. A., Gray, M. M., Casner, K. L., Barthelet, A., ... Kondratief, B. C. (2018). Narrow thermal tolerance and low dispersal drive higher speciation in tropical mountains. Proceedings of the National Academy of Sciences, 115(49), 12471-12476. doi:10.1073/pnas.1809326115

Pörtner, H. O., Peck, L., \& Somero, G. (2007). Thermal limits and adaptation in marine Antarctic ectotherms: an integrative view. Philosophical Transactions of the Royal Society B: Biological Sciences, 362(1488), 2233-2258. doi:10.1098/rstb.2006.1947

R Development Core Team (2017). R: A Language and Environment for Statistical Computing. Vienna, Austria: R Foundation for Statistical Computing.

Raschmanová, N., Miklisová, D., Kováč, L'., \& Šustr, V. (2015). Community composition and cold tolerance of soil Collembola in a collapse karst doline with strong microclimate inversion. Biologia, 70, 802-811. doi:10.1515/biolog-2015-0095

Raschmanová, N., Šustr, V., Kováč, L., Parimuchová, A., \& Miloslav Devetter, M. (2018) Testing the climatic variability hypothesis in edaphic and subterranean Collembola (Hexapoda). Journal of Thermal Biology, 78, 391-400. doi:10.1016/j.jtherbio.2018.11.004

Rex, M. A., Stuart, C. T.,Hessler, R. R., Allen, J. A., Sanders, H. L., \& Wilson, G. D. F. (1993) Globalscale latitudinal patterns of species diversity in the deep-sea benthos. Nature, 165, 636-639. doi:10.1038/365636a0 
Ribera, I., Fresneda, J., Bucur, R., Izquierdo, A., Vogler, A. P., Salgado, J. M., \& Cieslak, A. (2010). Ancient origin of a Western Mediterranean radiation of subterranean beetles. BMC Evolutionary Biology,10, 29. doi:10.1186/1471-2148-10-29

Rohde, K. (1996). Rapoport's rule is a local phenomenon and cannot explain latitudinal gradients in species diversity. Biodiversity Letters, 3, 10-13. doi:10.2307/2999704

Rizzo, V., Sánchez-Fernández, D., Fresneda, J., Cieslak, A., \& Ribera, I. (2015). Lack of evolutionary adjustment to ambient temperature in highly specialized cave beetles. BMC Evolutionary Biology, 15(1), 10. doi:10.1186/s12862-015-0288-2

Rubel, F., Brugger, K., Haslinger, K., \& Auer, I. (2017). The climate of the European Alps: Shift of very high resolution Köppen-Geiger climate zones 1800-2100. Meteorologische Zeitschrift, 26, 115-125. doi:10.1127/metz/2016/0816

Sánchez-Fernández, D., Rizzo, V., Cieslak, A., Faille, A., Fresneda, J., \& Ribera, I. (2016). Thermal niche estimators and the capability of poor dispersal species to cope with climate change. Scientific Reports, 6, 23381. doi:10.1038/srep23381

Sánchez-Fernández, D., Rizzo, V., Bourdeau, C., Cieslak, A., Comas, J., Faille, A., Fresneda, J., ... Ribera, I. (2018), The deep subterranean environment as a potential model system in ecological, biogeographical and evolutionary research. Subterranean Biology, 25, 1-7.

doi:10.3897/subtbiol.25.23530

Shah, A. A., Gill, B. A., Encalada, A. C., Flecker, A. S., Funk, W. C., Guayasamin, J. M., ... Ghalambor, C. K. (2017). Climate variability predicts thermal limits of aquatic insects across elevation and latitude. Functional Ecology, 31, 2118-2127. doi:10.1111/1365-2435.12906

Scheffers, B. R., Shoo, L., Phillips, B., Macdonald, S. L., Anderson, A., VanDerWal, J., ... Williams, S. E. (2017). Vertical (arboreality) and horizontal (dispersal) movement increase the resilience of vertebrates to climatic instability. Global Ecology and Biogeography, 26, 787-798. doi:10.1111/geb.12585

Scheffers, B. R., \& Williams, S. E. (2018). Tropical mountain passes are out of reach - but not for arboreal species. Frontiers in Ecology and Environment, 16, 101-108. doi:10.1002/fee.1764

Sheldon, K. S., Huey, R. B., Kaspari, M., \& Sanders N. J. (2018). Fifty years of mountain passes: a perspective on Dan Janzen's classic article. The American Naturalist, 191, 553-565. doi:10.1086/697046 
Smith, M. A. (2018). Janzen's mountain passes hypothesis is comprehensively tested in its fifth decade. Proceedings of the National Academy of Sciences, 115(49), 12337-12339. doi:10.1073/pnas. 1817774115

Stevens, G. C. (1989). The latitudinal gradients in geographical range: how so many species co-exist in the tropics. The American Naturalist, 133, 240-256. doi:10.1086/284913

Sunday, J. M., Bates, A. E., \& Dulvy, N. K. (2011). Global analysis of thermal tolerance and latitude in ectotherms. Proceedings of the Royal Society of London B: Biological Sciences, 278(1713), 18231830. doi:10.1098/rspb.2010.1295

Taylor, R. G., Scanlon, B., Döll, P., Rodell, M., Van Beek, R., Wada, Y., ... \& Konikow, L. (2013). Ground water and climate change. Nature Climate Change, 3, 322-329. doi:10.1038/nclimate1744

Tibshirani, R., Walther, G., \& Hastie, T. (2001). Estimating the number of clusters in a data set via the gap statistic. Journal of the Royal Statistical Society: Series B (Statistical Methodology), 63, 411-423. doi:10.1111/1467-9868.00293

Veter, N. M., DeSantis, L. R. G., Yann, L. T., Donohue, S. L., Haupt, R. J., Corapi, S. E., ... Velkovsky, S. M. (2013). Is Rapoport's rule a recent phenomenon? A deep time perspective on potential causal mechanisms. Biology Letters, 9, 20130398. doi:10.1098/rsbl.2013.0398

Wessel, A., Hoch, H., Asche, M., von Rintelen, T., Stelbrink, B., Heck, V., ... Howarth, F. G. (2013). Founder effects initiated rapid species radiation in Hawaiian cave planthoppers. Proceedings of the National Academy of Sciences, 110(23), 9391-9396. doi:10.1073/pnas.1301657110

Wu, G. C., \& Wright, J. C. (2015). Exceptional thermal tolerance and water resistance in the mite Paratarsotomus macropalpis (Erythracaridae) challenge prevailing explanations of physiological limits. Journal of Insect Physiology, 82, 1-7. doi:10.1016/j.jinsphys.2015.08.002

Zagmajster, M., Eme, D., Fišer, C., Galassi, D., Marmonier, P., Stoch, F., ... \& Malard, F. (2014). Geographic variation in range size and beta diversity of groundwater crustaceans: insights from habitats with low thermal seasonality. Global Ecology and Biogeography, 23, 1135-1145. doi:10.1111/geb.12200

\section{SUPPORTING INFORMATION}

Additional supporting information may be found in the online version of this article.

Appendix S1. Alternative results using seasonal cave temperature values to estimate $\Delta T$. 